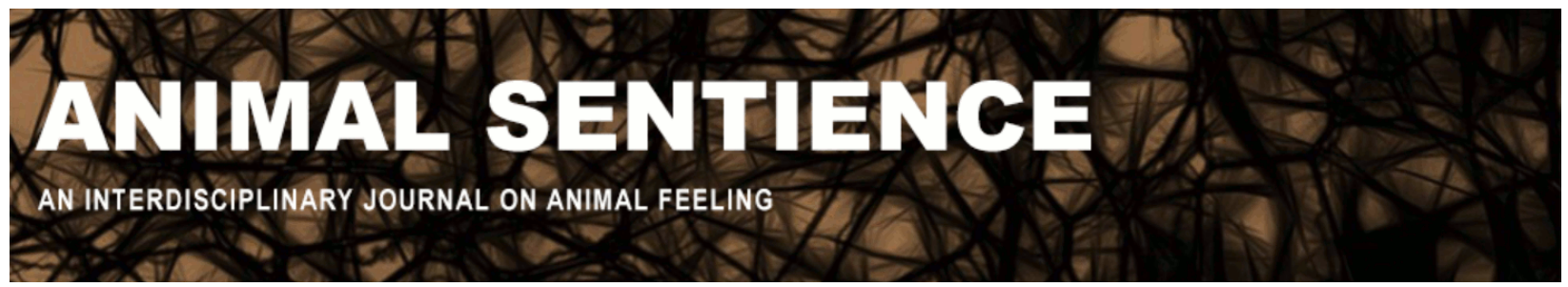

Mehrkam, Lindsay R. (2019) A behaviorist approach to sheep cognition, intelligence, and welfare. Animal Sentience 25(37)

DOI: $10.51291 / 2377-7478.1486$

Date of submission: 2019-06-10

Date of acceptance: 2019-06-22

(c)

This article has appeared in the journal Animal

Sentience, a peer-reviewed journal on animal

cognition and feeling. It has been made open access,

free for all, by WellBeing International and deposited

in the WBI Studies Repository. For more information,

please contact

wbisr-info@wellbeingintl.org.

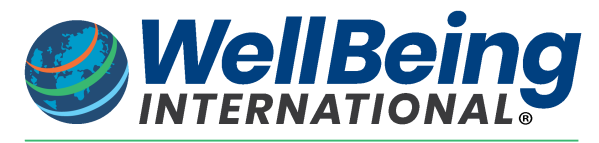

SOLUTIONS FOR PEOPLE, ANIMALS AND ENVIRONMENT 


\title{
A behaviorist approach to sheep cognition, intelligence, and welfare
}

\author{
Commentary on Marino \& Merskin on Sheep Complexity
}

\author{
Lindsay R. Mehrkam \\ Department of Psychology \\ Monmouth University
}

\begin{abstract}
Marino \& Merskin's review sheds light on the complexity of the mind, learning, and cognition of sheep. Readily observable behavior has value in its own right for promoting the wellbeing of animals. A behavior-analytic approach can add substantially to the understanding of sheep as individuals as well as their learning capacities. The findings can also be applied to arranging their environments to promote their well-being as well as behavioral change in those responsible for their care and management.
\end{abstract}

Lindsay R. Mehrkam is an assistant professor of psychology, board-certified behavior analyst, and applied animal behaviorist. Her research focuses on designing and evaluating behavioral interventions to promote both human and animal welfare in society. Website

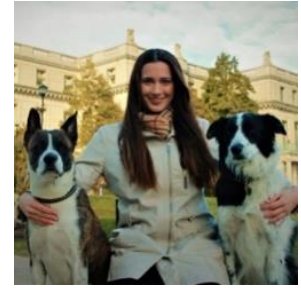

Marino \& Merskin's (2019) (M\&M) review provides a useful and well-supported argument for sheep as socially and cognitively complex beings, convincingly countering the long-standing misrepresentation of sheep as simple-minded creatures. This is important but no surprise to those engaged in the formal study of animal learning, behavior, and cognition. It is a welcome addition to the growing literature showing the rich psychological capabilities of a wide range of species from invertebrates and fish to other more charismatic domestic and exotic animals.

Many of the studies underlying M\&M's conclusion that sheep are complex, social, intelligent, and individualistic are highly anthropocentric in their methodology, but anthropomorphizing can be useful: attributing human traits to nonhuman animals may help people who do not have relationships with them to draw effective analogies with their own experiences. This may increase their concern for the welfare of that species or that individual animal. It is also important, however, to modify these anthropocentric methods in more speciesappropriate studies to get a more accurate picture of true sheep capabilities.

Value of a Behaviorist Perspective: Environment-Behavior Relations. If M\&M's hope is to facilitate further research and induce changes in human behavior for the sake of sheep and farm animal welfare, then we need to consider the controlling variables that influence how we perceive and treat farm animals. This is a task for which behaviorism - the science of behavior - is wellsuited. The major tenet of behaviorism is that we can understand the causes of behavior as a natural phenomenon and that the principal locus of those causes is the individual's environment (Skinner, 1938). There is a misconception, especially in cognitive psychology, that behaviorists believe that animals are just "stimulus-response" machines, that only what we can observe an 
animal doing outwardly exists, and that nonhuman animals do not have cognitions, emotions, or higher-level processes. This is simply incorrect. Behaviorists do not focus on observable behavior because they reject emotions or other internal capabilities: they give priority to behavioral measures because those are readily amenable to observation, prediction, and control.

Foster, Temple, and Poling (1997) called for the application of behavior analysis to farm animal welfare, citing food and housing preferences of animals, behavioral economics, and sensation and perception as especially ripe areas for study. One reason behaviorism is so heavily resisted as outdated is that many underestimate how much environment and experiences affect behavior. The inaccurate view of sheep as simple-minded is related to our own reinforcement history and the ways we are typically exposed to sheep. Their widespread use as commodities and the way they are currently housed - can further reinforce our erroneous assumption that they are not individuals, do not have individual preferences, and do not need opportunities for emotional or social complexity or even for learning. Sheep may act docile and show little independent problem-solving because the environment in which they are housed contributes to their poor welfare and learned helplessness. Where animals have limited control over their environment and lack adequate space and opportunity to engage in natural species-typical behaviors such as social play, the outcome is not because of their genes but because of their environment. M\&M are right to recommend that there should be more noninvasive research, done in sanctuaries, on sheep and farm animals. A behavioral approach has clear advantages over other methodologies to achieve this goal.

Applied Behavior Analysis in Animal Welfare and Management. Applied behavior analysis (ABA) uses behavioral principles to solve societal problems or to understand or modify socially significant behavior (Baer, Wolf, \& Risley, 1968). It is best-known in applications to human psychology (e.g., autism intervention, smoking cessation, educational performance). ABA has also been successfully extended to animal behavior (e.g., Alligood, Dorey, Mehrkam, \& Leighty, 2017; Maple \& Segura, 2015; Mehrkam \& Dorey, 2015). For sheep housed in sanctuaries and other facilities, ABA can evaluate techniques such as positive reinforcement training and environmental enrichment for reducing problem behaviors (e.g., stereotypic behavior) and increasing adaptive behaviors (e.g., social or solitary play, exploratory behavior, choice) as well as positive changes in emotions and physiological responses. M\&M cite many examples of behavioral indicators of positive (e.g., social play) and negative emotions in sheep (e.g., ear position, vigilance, body posture, avoidance or attempts to escape, and so on). Participating in many of the tests discussed by M\&M may also function as behavioral or cognitive enrichment (Manteuffel, Langbein, \& Puppe, 2009; Meehan \& Mench, 2007). They could be used to give sheep and other farm animals increased control of their environments.

Finally, the goal of promoting positive behavioral changes does not concern only the animals. ABA can also be useful in identifying and prescribing positive behavioral change in people - whether consumers, caretakers, or advocates - in society. For example, does early life exposure to farm animals promote improved perceptions about animals' learning or emotional capabilities? Could early exposure inform behavioral choices or decisions about the ethical treatment of animals later in life? What sorts of training programs might be effective to increase the use of humane methods of husbandry that ensure the safety and welfare of nonhuman animals and people alike? Such initiatives will be best achieved with open communication between academic 
and industry scientists and professionals, including farm animal sanctuary workers, who have perhaps the most intimate relationship with individual animals. All should work collectively toward the common goal of promoting the best quality of life for sheep and other animals.

\section{References}

Alligood, C. A., Dorey, N. R., Mehrkam, L. R., \& Leighty, K. A. (2017). Applying behavior-analytic methodology to the science and practice of environmental enrichment in zoos and aquariums. Zoo Biology, 36(3), 175-185.

Baer, D. M., Wolf, M. M., \& Risley, T. R. (1968). Some current dimensions of applied behavior analysis 1. Journal of Applied Behavior Analysis, 1(1), 91-97.

Foster, T. M., Temple, W., \& Poling, A. (1997). Behavior analysis and farm animal welfare. The Behavior Analyst, 20(2), 87-95.

Manteuffel, G., Langbein, J., \& Puppe, B. (2009). From operant learning to cognitive enrichment in farm animal housing: Bases and applicability. Animal Welfare, 18(1), 87-95.

Maple, T. L., \& Segura, V. D. (2015). Advancing behavior analysis in zoos and aquariums. The Behavior Analyst, 38(1), 77-91.

Marino, L., \& Merskin, D. (2019). Intelligence, complexity, and individuality in sheep. Animal Sentience 25(1).

Meehan, C. L., \& Mench, J. A. (2007). The challenge of challenge: Can problem solving opportunities enhance animal welfare?. Applied Animal Behaviour Science, 102(3-4), 246261.

Mehrkam, L. R., \& Dorey, N. R. (2015). Preference assessments in the zoo: Keeper and staff predictions of enrichment preferences across species. Zoo Biology, 34(5), 418-430.

Skinner, B. F. (1938). The behavior of organisms. New York: Appleton-Century-Crofts. 